\title{
¿QUÉ CONSTITUCIÓN PARA CATALUÑA? UNA APROXIMACIÓN CRÍTICA A LOS PROYECTOS CONSTITUCIONALES DEL PROCÉS
}

\author{
CARLOS FLORES JUBERÍAS \\ Catedrático (A) de Derecho Constitucional \\ Universidad de Valencia
}

SUMARIO

I. Introducción. II. Los antecedentes. III. Los proyectos constitucionales del Procés. IV. La cuestión de las formas. V. Conclusiones.

\section{INTRODUCCIÓN}

Los éxitos electorales cosechados por los partidos nacionalistas que desde 2010 dirigen las principales instituciones de autogobierno de Cataluña, la persistencia con la que en los últimos tiempos han venido haciendo patente su intención de separarse de España — bien de manera negociada, bien mediante una declaración unilateral de independencia-, y la también insoslayable existencia de una corriente de opinión numéricamente importante y socialmente muy influyente favorable a esa separación, han obligado a prestar una atención creciente no solo al modo en el que esa disociación podría llevarse a cabo, sino también a cuales serían los escenarios que se abrirían en el supuesto de que esta opción se llegara a imponer. Como consecuencia de ello, de un tiempo a esta parte vienen siendo cada vez más numerosos los análisis que —obviando el hecho de que la efectiva separación de Cataluña no solo es jurídicamente inviable, sino también políticamente indeseable - han venido dando por supuesto que ésta se materializará de alguna manera en un futuro inmediato, y han pasado a centrarse en el análisis de cómo quedaría configurada esa hipotética Cataluña independiente.

En este plano, salta a la vista que la mayor parte de los estudios - tanto los preparados por la larga nómina de expertos al servicio de las instituciones de la Generalitat de Catalunya con el fin de hacer pedagogía de la segregación, como 
los debidos a analistas independientes de dentro y de fuera de Cataluña, tanto favorables como contrarios a la misma- han incidido de manera prioritaria en tres cuestiones clave: las consecuencias económicas de la independencia de Cataluña, la posición en la que una Cataluña independiente quedaría en relación con la Unión Europea, y la posibilidad de que los ciudadanos de ese hipotético nuevo Estado pudieran seguir disfrutando de la nacionalidad española, y de los derechos que le son inherentes. En cambio, siguen siendo llamativamente escasos los análisis en torno al modelo político del que se podría dotar ese hipotético Estado catalán, de modo que son ya varias las ocasiones en las que los ciudadanos de Cataluña se han visto instados a pronunciarse en las urnas - y en las calles - sobre la cuestión de su permanencia en España, sin tener más que una muy remota idea del tipo de régimen político que podría estar esperándoles a la vuelta de la esquina.

Esa falta de transparencia no ha sido en modo alguno fruto de la inexistencia de propuestas a este respecto, toda vez que éstas no han hecho más que aflorar casi sin cesar durante los últimos años, y en especial durante los últimos meses. De modo que es obligado pensar que quizás la postposición del debate sobre el sistema político que se propone para una hipotética Cataluña independiente con el que los principales partidos del arco parlamentario catalán vienen jugando constituya una estrategia encaminada, bien a no alienar a ningún posible seguidor de esta opción presentándole fórmulas políticas con las que pudiera estar en desacuerdo, bien a evitar la fragmentación del campo político favorable a la independencia, cuya extrema diversidad ideológica hace plausible un consenso de duración muy limitada.

En este contexto, el primer objetivo de este trabajo es el de levantar acta de los sucesivos proyectos o borradores de constitución para una futura Cataluña independiente surgidos a la sombra del actual repunte del secesionismo, para a continuación tratar de desbrozar su contenido, advertir de sus carencias, poner de relieve los aspectos más relevantes —y también más controvertidos- de su articulado, y valorar sus posibilidades reales de llegar a convertirse alguna vez en norma jurídica, para —en última instancia — tratar de hallar algunos rasgos comunes a todos ellos que permitan entender mejor los objetivos últimos del secesionismo catalán en lo tocante a la configuración constitucional del Estado que aspira a conformar.

\section{LOS ANTECEDENTES}

Viniendo como viene de lejos, el nacionalismo catalán ha jalonado su historia de proyectos constitucionales llamados a vertebrar una hipotética República Catalana en el momento en que su objetivo último hubiera logrado materializarse.

Dejando de lado — siquiera sea por razones de espacio — los gestados en el último tercio del siglo XIX al amparo del pujante movimiento federalista cata- 
lán $^{1}$, podría decirse que, el de mayor relevancia y el que mayor huella —al menos, en el plano simbólico- ha llegado a dejar sería el gestado en 1928, cuando la Assemblea Constituent del Separatisme Català reunida en La Habana, bajo la presidencia de Francesc Macià procedió a aprobar una «Constitució Provisional de la República Catalana» ${ }^{2}$. Obra personal de José Conangla y Fontanilles $^{3}$, la conocida coloquialmente como Constitució de l'Havana constaba de 302 artículos de dicción más bien sintética, estructurados en 36 títulos. Definía a Cataluña como un «Estado independiente y soberano, que adoptaba como forma de gobierno «la República técnico-democrática representativa»; declaraba como su bandera oficial la ahora popular estelada; declaraba abolidos los límites provinciales, ordenando su sustitución por las tradicionales comarcas; contemplaba una amplio catálogo de derechos, a caballo entre la tradición («La casa catalana es el fundamento de las libertades y el segurísimo refugio de los catalanes. Como domicilio de la familia natural, la casa catalana es inviolable», rezaba, a modo de ejemplo, el artículo 11) y la modernidad (entre los que se contaban el sufragio universal y secreto, la libertad de cultos, la igualdad de derechos entre hombres y mujeres, y la prohibición de la pena de muerte o de la prisión por deudas); así como un amplio abanico de medidas regeneradoras (el art. 51, por ejemplo, prohibía la gandulería y la mendicidad, y el 52 las corridas de toros, el boxeo «y todo deporte que tienda a embrutecer al pueblo»), así como otras tantas de intencionalidad catalanizadora, entre las que se contaban la obligación de saber hablar y escribir el catalán tanto para ser elector como elegible .

La Constitució Provisional — que caería mayormente en el olvido al proclamar Macià la República Catalana y conformarse más tarde con el Estatut de 1932 — $^{5}$ contemplaba también la elección indirecta del jefe de Estado, un parlamento unicameral, un ejército y una marina militar propia; y, en última instancia, la posibilidad de una confederación, renovable cada seis años, con otros estados ibéricos.

Tras el breve paréntesis de la Segunda República, en la que Cataluña apenas disfrutó de autonomía entre 1932 y 1934, y entre 1936 y $1939^{6}$, y con la Gene-

1 Véase la recopilación de González Casanova, J. A. en Federalisme i autonomia a Catalunya (18681938): documents, Curial, Barcelona, 1974, p. 864, y en paralelo, Federalismo y Autonomía: Cataluña y el Estado Español 1868-1938, Crítica, Barcelona, 1979, p. 368.

2 Constitució provisional de la República Catalana: aprovada per l'Assemblea Constituent del Separatisme Català reunida a l'Havana durant els dies 30 de setembre, 1 i 2 d'octubre de 1928, La Habana, 1928 (disponible en la Biblioteca Digital Hispánica, en línea en www.bne.es/es/Catalogos/BibliotecaDigitalHispanica/Inicio/index. html).

3 Vid. Conangla i Fontanilles, J.: La Constitució de l'Havana i altres escrits, Edicions de la Magrana /Diputació de Barcelona, Barcelona, 1986.

4 Véase al respecto, Ferrán Oliva, J. M.: La Constitució catalana de L'Havana, Pagès Editors, Lérida, 2005.

5 Falguera, O.: «La Constitució de la República catalana, 1928», El Temps n. ${ }^{\circ} 1009$ (2003), pp. $46-51$.

6 Véase al respecto, entre otros, Gerpe LANDín, M.: L'Estatut d'Autonomia de Catalunya i l'Estat integral, Edicions 62, Barcelona, 1977 o PALOMEro, R.: República i autonomía: La Generalitat republicana (19311936), Barcanova, Barcelona, 1991. 
ralitat ya restaurada y plenamente operativa al amparo del Estatut de $1979^{7}$, la entonces recién creada formación independentista Catalunya Lliure ${ }^{8}$, hizo público un «Avantprojecte de Constitució Catalana», datado en Vinaroz el 14 de abril 1991, con la intención iniciar con él «un debate amplio, sin adscripciones partidistas, en el que se enmiende y mejore el texto y pueda aprobarse, por último, un proyecto de Constitución Catalana que haga más cercana y realizable la independencia de Cataluña» — por más que en un momento en el que el independentismo era más que minoritario, auténticamente marginal, el documento pasara mayormente desapercibido? .

En coherencia con los planteamientos programáticos de Catalunya Lliure, su Avantprojecte declaraba que las fronteras de la futura República Catalana comprenderían no solo los territorios de Cataluña, sino también los de las comarcas de la Comunidad Valenciana, la Cataluña francesa, las Islas Baleares, y Andorra (art. 2), si bien admitía que las comarcas no catalanoparlantes pudieran separarse de Cataluña si así lo decidieran en plebiscito (art. 3); al tiempo que en coherencia con sus estrategias de acción, y no sin antes haber repudiado las guerras de agresión y de conquista, reconocía la legitimidad «de todas las formas de lucha para la liberación nacional y en contra de cualquier tipo de agresión y ocupación» (art. 16). Por lo demás, contemplaba un parlamento de trescientos miembros elegibles por un sistema mayoritario, cada cuatro años, y en circunscripciones comarcales; un Presidente — catalán de nacimiento — también de elección popular, dotado de funciones moderadoras y provisto de un mandato de seis años; un Presidente del Gobierno de elección y extracción parlamentaria; y un poder judicial integrado por «jueces municipales» $\mathrm{y}$ «comarcales» de elección popular, y por «jueces nacionales» elegidos por el parlamento. Y cerraba su articulado con una amplia serie de transitorias, en las que entre otras cosas se privaba de la posibilidad de obtener la ciudadanía catalana a quienes «hubieran formado parte de las fuerzas de ocupación españolas o francesas», y solo se reconocían los derechos laborales adquiridos a «los ciudadanos catalanes miembros de los cuerpos de funcionarios de los antiguos estados ocupantes español y francés o trabajadores de empresas incautadas por la República Catalana, que no hayan colaborado con las fuerzas de ocupación».

Mucho más cercano en el tiempo, y en consecuencia más estrechamente ligado a los factores que han configurado la actual situación política de Cataluña, se

7 Véase al respecto, entre otros, PAGÈs, J.: La autonomía política de Cataluña: orígenes, competencias y organización de la Generalidad, Departament de la Presidència, Barcelona, 1996 o Castellà, J. M.: La función constitucional del estatuto de autonomía de Cataluña, Institut d'Estudis Autonòmics, Barcelona, 2004.

8 Constituída en 1989, primero como coalición y luego como partido, a partir de la confluencia del Moviment de Defensa de la Terra-PSAN y el Front Nacional de Catalunya, Catalunya Lliure fue una de las primeras organizaciones declaradamente independentistas. Su trayectoria fue sin embargo sumamente breve, toda vez que la organización se disolvió a finales de 1996, después de que una buena parte de sus miembros se hubieran integrado ya en Esquerra Republicana de Catalunya. Vid. BAssA, D.: L'independentisme català, 19791994, Llibres de l'Índex, Barcelona, 1994.

9 Consúltese en www.academia.edu/2486812/Avantprojecte_de_Constitució_Catalana. 
hallaría el llamado «Projecte de Constitució de l'Estat lliure de Catalunya» ${ }^{10}$ : una iniciativa promovida desde Esquerra Republicana y debida a las plumas de Joan Ridao y Raimon Escudé, por la que el partido relanzaba y reescribía un Avantprojecte d'Estatut Nacional de Catalunya gestado tres años antes, justo en el momento en el que comenzaba a tomar fuerza la posibilidad de sustituir el Estatut de 1979 por un texto más ambicioso ${ }^{11}$.

Tratando de revisar al alza las propuestas de reforma estatutaria ya avanzadas por el PSC y CiU la iniciativa de Esquerra se presentaría no como un proyecto más de Estatuto de Autonomía, sino como la Constitución de un Estado soberano, merced a la cual —y este sería su aspecto mas señalado y, en aquellos momentos, más rompedor-Cataluña se convertiría en un Estado libre asociado voluntariamente al Reino de España, en los términos previstos por ese Estatuto y por las normas de la Constitución española que le siguieran siendo de aplicación (art. 1.3), entendiendo que de ese modo quedaba ejercido el derecho de autodeterminación que le correspondía como nación para establecer libremente su régimen político, social y económico. La idea, inequívocamente inspirada en el recientemente descarrilado «Plan Ibarretxe» se hallaba en todo caso concebida como un paso intermedio entre las fórmulas autonómicas salidas de la transición y la perspectiva de un futuro en el que hubieran desaparecido los condicionamientos derivados de aquel momento político. El texto contemplaba asimismo la el derecho «permanente» de las comarcas «del País Valencià i de les Illes Balears» a integrarse en el Estat Lliure Associat de Catalunya, así como la posibilidad de que a propuesta de la Generalitat las fronteras estatales de Francia y España, y dentro de España las de las comunidades autónomas limítrofes con Cataluña, pudieran alterarse de manera concertada (art. 2). Por lo demás, el Proyecto establecía la oficialidad del catalán y ordenaba el fomento de su uso y reconocimiento (art. 3); contemplaba un poder judicial catalán y un mando único de la policía; preveía la participación directa de las instituciones catalanas en la toma de decisiones de la Unión Europea; determinaba que la Generalitat tendría el control sobre los impuestos que pagaran los catalanes a través de un sistema de concierto similar al existente en el País Vasco; y preveía asimismo la posibilidad de convocar en el futuro un referéndum para decidir en torno a la completa independencia de Cataluña.

A la postre, el accidentado proceso de tramitación del Estatut de 2006, en el que Esquerra acabaría votando a favor del texto salido del Parlament, pero oponiéndose al salido del Congreso $-\mathrm{y}$, naturalmente, también a los recortes introducidos en él por el Tribunal Constitucional-, alejarían a su propio proyecto del

10 Projecte de Constitució de l'Estat lliure de Catalunya (con prólogo de Josep-Lluís Carod-Rovira e introducción de J. Ridao y R. Escudé), Mediterránea, Barcelona, 2003. El texto puede también consultarse en la web del partido http://www.esquerra.cat/documents/arxiulestatut03.pdf

11 «Carod presenta el projecte de Constitució de l'Estat Lliure de Catalunya, el projecte d'Estatut Nacional d'ERC», en línea en www.esquerra.cat. 
foco del debate, para acabar arrinconado a medida que las posiciones del partido fueran radicalizándose cada vez más.

Sería en ese contexto de radicalización de posturas, cuyo punto de arranque podría muy bien situarse en la publicación de la STC 31/2010, sobre el Estatuto de Autonomía de Cataluña, y en las subsiguientes — en realidad, también antecedentes - reacciones de los principales actores políticos catalanes, en donde habría que ubicar las propuestas constitucionales a cuyo análisis vamos a dedicar el grueso de este trabajo.

\section{LOS PROYECTOS CONSTITUCIONALES DEL PROCÉS}

\section{El Proyecto de Reagrupament}

Anunciada en marzo de 2010 por el ya entonces ex Conseller de Governació Joan Carretero ${ }^{12}$ como «la primera ley que los diputados que representen a Reagrupament en el Parlamento de Cataluña presentarán para que se apruebe», olvidada a continuación, y recuperada de nuevo en abril del 2014, al tiempo que otras propuestas constitucionales empezaban a tomar forma, la llamada «Constitució de Catalunya» ${ }^{13}$ será un texto estrechamente ligado desde su nacimiento a aquella formación política y en consecuencia abocado a tener una trascendencia política tan escasa como su éxito electoral ${ }^{14}$.

De su texto llama la atención, en primer lugar, su inusitada brevedad, en segundo lugar la enorme descompensación entre su parte dogmática y su parte orgánica, y por último - y en lógica consecuencia de lo anterior- sus innumerables lagunas, que hacen difícil incluso su conceptualización como una auténtica constitución.

En cuanto a lo primero, el texto de esta autodenominada «Constitució de Catalunya» cuenta con apenas 26 artículos, de redacción más bien escueta —en al-

12 Alcalde de Puigcerdá entre 1995 y 2003, Carretero fue Conseller de Governació i Administracions Publiques de la Generalitat de Catalunya desde diciembre de 2003 hasta abril de 2006, en vísperas de la salida de Esquerra Republicana de Catalunya del Govern encabezado por Pasqual Maragall. Tras haber formado una corriente crítica dentro de Esquerra (febrero de 2007) y haber optado sin éxito a la Secretaría General del partido (junio de 2008), Carretero saldría de Esquerra para dar a luz una nueva formación independentista denominada Reagrupament.

13 El texto puede consultarse en la web del partido www.reagrupament.cat/. Aquí y en adelante, última consulta, 24.12.2015.

14 Creada a finales de 2009 al objeto de contribuir a «la defensa, el fomento, la difusión y el estudio del independentismo y el republicanismo en el ámbito de Cataluña», y «el fortalecimiento de la base social del independentismo en los Países Catalanes» (Associació Reagrupament Independentista. Estatuts). Reagrupament concurrió a las entonces inminentes elecciones al Parlamento de Cataluña del 28 de noviembre de 2010, cosechando apenas un $1,27 \%$ de los votos, y quedando muy lejos del mínimo necesario para alcanzar representación parlamentaria. En octubre de 2013 anunciaría su integración en CDC y en diciembre de 2015 concurriría a las elecciones generales del 20-D como tercer integrante de la Plataforma Democràcia i Llibertat. 
gunos casos tanto como para no superar las diez palabras-, encuadrados a su vez en cuatro títulos, a los que se añaden cuatro «Disposiciones transitorias y finales» - de las que en puridad, dos son transitorias, y otras dos derogatorias- En total, no más de cinco páginas de texto.

El apuntado desequilibrio entre la parte dogmática y la parte orgánica de la constitución queda patentizado por el hecho de que su texto apenas dedique dos artículos —el 22 y el 23, que integran por sí solos el llamado Título III. «La organización del Estado»— a esta última cuestión. Aunque a la vista de su literalidad, que no pasa de ser de ser una limitadísima acumulación de obviedades y remisiones normativas ${ }^{15}$ quizás sería más razonable sostener que el proyecto constitucional de Reagrupament sencillamente obvia la cuestión de cómo serán las instituciones de la futura Cataluña independiente, y queda en consecuencia limitado a una tampoco demasiado amplia declaración de derechos, precedida —eso síde una rotunda afirmación soberanista ${ }^{16}$.

Como cabría esperar, la cuestión de la soberanía aparece como capital en el proyecto constitucional de Reagrupament: tanto, que comprende una cuarta parte de sus artículos - los que van del 1 al 7 - en los que una vez proclamado que «Cataluña es un Estado de Derecho, independiente, democrático y social» (art. 1), en el que «la soberanía nacional pertenece al pueblo de Cataluña, que la ejerce directamente o mediante sus representantes» (art. 2), se pasa a describir su territorio (art. 3), su capital (art. 4), su lengua (art. 5), las condiciones para la adquisición, conservación y pérdida de la condición nacional de catalán (art. 6) y sus símbolos (art. 7). A este respecto, la ambigüedad pugna con la inconsistencia: la primera, a la hora de definir cual sea el territorio del nuevo Estado ( El territorio de Cataluña se corresponde con los límites geográficos de Cataluña», reza el men-

15 Dada la brevedad de ambos artículos, no será excesiva su transcripción literal: Artículo 22. «Los tres poderes fundamentales del Estado son el poder legislativo, el poder ejecutivo y el poder judicial. Los poderes legislativo, ejecutivo y judicial están separados. Las leyes regularán los órganos que formarán cada uno de los poderes del Estado así como su composición, atribuciones y funciones.» Artículo 23: «Se regularán por ley las atribuciones y funciones de los municipios y órganos supramunicipales».

16 Esta carencia quedaría aparentemente paliada por la remisión que la Disposición segunda hace al vigente Estatut —al que curiosamente se refiere como «Ley Orgánica 6/2006, de 19 de julio, de reforma del Estatuto de Cataluña»— al afirmar que «Mientras no se dicten las leyes que regulen la composición, atribuciones y funciones de los poderes legislativo, ejecutivo y judicial, estas atribuciones serán ejercidas por el Parlament de Catalunya, el President, el Govern de la Generalitat y los órganos judiciales, en la forma establecida». La afirmación resulta doblemente criticable: por un lado, porque da por sentado que poder judicial español —que es a quien se está refiriendo, por más que rehúse a mentarlo por su nombre, la alusión a «los órganos judiciales» que acabamos de transcribir — estará dispuesto y además en condiciones de ejercer esas funciones una vez la independencia de Cataluña se hubiera materializado y hasta que las futuras instituciones catalanas tuvieran a bien constituir un poder judicial propio; y por otro, porque con esta alusión a «las leyes» como instrumento normativo para la regulación de la composición, atribuciones, y funciones de los tres poderes del Estado se está sencillamente desconstitucionalizando por entero el sistema institucional de esa hipotética Cataluña independiente. De ahí nuestra ya avanzada conclusión de que el Proyecto Carretero, lejos de ser lo que su nombre parece sugerir, es un chusco intento de hurtar a la ciudadanía de Cataluña las garantías de las que el constitucionalismo ha venido haciendo bandera desde hace al menos dos siglos.

UNED. Teoría y Realidad Constitucional, núm. 37, 2016, pp. 405-433 
cionado art. 3, cayendo en la tautología) o cuáles sean sus símbolos ( Los símbolos de Cataluña son la bandera, la fiesta nacional y el himno nacional», reza el art. 7 , sin considerar necesaria precisión de ningún tipo); y la segunda a la hora de definir la cuestión de la nacionalidad. A este respecto, el referido artículo 6 establece que «los ciudadanos del País Valenciano, las Islas Baleares, Cataluña Norte, la Franja de Poniente y el Alguer tienen garantizada la condición nacional de catalanes, si lo solicitan», obviando que ninguno de estos territorios dispone de leyes propias relativas a su nacionalidad, y dejando en consecuencia en manos de los legisladores español francés e italiano la determinación última de quienes vayan a ser ciudadanos de la futura Cataluña independiente. Por último, también en lo tocante a la lengua la ambigüedad es la tónica, toda vez que tras afirmar que «El catalán es la lengua propia, nacional y oficial de Cataluña», el artículo 5 proclama la «libertad lingüística», sin que sea posible aprehender si ésta es simplemente la capacidad para elegir la lengua en la que uno desee expresarse en sus comunicaciones privadas, o comporta alguna facultad más.

En cuanto a la tabla de derechos fundamentales que integra el Título II, y constituye el grueso del Proyecto (arts. 9 a 21), si algo llama poderosamente la atención es su indisimulable seguidismo respecto del texto constitucional de 1978 en lo tocante a los enunciados (algunos literalmente transcritos), y su sangrante inferioridad respecto de éste en lo relativo a las garantías. Y es que el proyecto constitucional de Reagrupament carece de cualquier sistema de defensa de los derechos y, por no tener, no contiene siquiera una cláusula en la que se enumeren las fuentes de su Derecho, o se proclame la supremacía de la Constitución. Así las cosas, sus dos innovaciones más llamativas son la contenida en el artículo 20, que rebaja la mayoría de edad hasta los dieciséis años, y la del artículo 11, que al afirmar que «Nadie puede ser perjudicado o favorecido por razón de su origen, su raza, su nacimiento, sus convicciones, sus opiniones o su situación social, o cualquier otra condición personal» implicaría con su puesta en práctica la proscripción de todas las medidas de discriminación positiva actualmente en vigor.

Por último, el Título IV, relativo a la reforma de la Constitución ahonda en el absurdo de los artículos precedentes al diferenciar (art. 24) entre una modificación total y una parcial de la constitución, para acto seguido (arts. 24 y 25) establecer que ambas podrán ser iniciadas bien a instancias del pueblo mediante una iniciativa legislativa popular, bien a instancias del legislativo, y que también ambas deberán ser sometidas a referéndum popular, sin que de ello quepa deducir la razón de ser de la distinción antedicha.

A la vista de todo ello, no cabe sino sostener que el proyecto constitucional de Reagrupament apenas merita el título con el que se le presenta de «Constitució de Catalunya». Es un texto técnicamente defectuoso, indefinible ideológicamente, menos generoso y mucho menos garantista en lo tocante a los derechos que el que ahora rige en Cataluña, e inexplicablemente silente en lo tocante a las instituciones, cuya gestación solo cabe explicar como una operación de marketing político encaminada a poner de relieve la voluntad de sus promotores de dotar a 
Cataluña de todos los atributos propios de un Estado independiente, pero sin ambición —ni opciones - de llegar a convertirse nunca en la auténtica Constitución de Cataluña.

\section{El Proyecto Vidal-Aparicio}

Puesto en marcha a finales de 2013 al objeto de gestar un primer borrador de constitución para una Cataluña independiente, generar a partir de éste un debate ciudadano sobre el tipo de gobierno que Cataluña debería tener, incorporar las propuestas de la sociedad civil al borrador inicialmente propuesto, y finalmente aportar el proyecto resultante a las instituciones que en el futuro vayan a abordar la redacción de la Constitución de Cataluña — con el propósito, en suma, de que la catalana sea «la primera constitución del mundo construida a partir de las aportaciones de la gente, la primera que nazca de abajo hacia arriba, y no de arriba hacia abajo»— ${ }^{17}$ Constitucio.cat hizo su primera aparición pública de la mano de Oriol Vidal-Aparicio ${ }^{18}$ con ocasión de la presentación de su proyecto en el histórico Ateneo Barcelonés el 31 de enero de 2015.

Se trata, de nuevo, de un texto breve -integrado por tan solo 63 artículos y seis transitorias, recogidos en apenas catorce páginas $-{ }^{19}$ pero en el que sin embargo no se detectan lagunas de relevancia, y que se abre con la bienintencionada declaración de que los ciudadanos de Cataluña «no somos enemigos de nadie y sí hermanos de todos los pueblos, que buscamos la fraternidad y el respeto, y que ofrecemos nuestro esfuerzo por el bien de la Humanidad y el avance de los derechos fundamentales y las libertades para todos los habitantes del mundo», y con la proclamación como principios políticos que lo fundamentan de «el republicanismo, la separación de poderes, la democracia participativa, la eficiencia administrativa y las garantías individuales de los ciudadanos frente a la administración del Estado».

En punto a la cuestión de los derechos y los deberes, regulados en su Título Segundo, el Proyecto Vidal-Aparicio llama poderosamente la atención por sus desequilibrios. Y es que en medio de una dicción caracterizada por la sobriedad y enteramente ajena a la afectación retórica tan común en otros textos constitucionales, en la que los derechos más importantes quedan constitucionalizados las

17 Véase Constitucio.cat. Proposta de text per a la Constitució de l'Estat Català, en www.constitucio.cat.

18 O. Vidal-Aparicio es licenciado en Periodismo por la Universidad Autónoma de Barcelona y Máster en Ciencias Políticas por la Arizona State University, y desde 2008 enseña constitucionalismo estadounidense y política internacional en el Glendale Community College de Arizona (EEUU). Es autor del libro 500 Preguntas al Nacionalismo Español (2006). Desde noviembre de 2013 forma parte del proyecto Constitucio.cat, del que es portavoz, y se halla igualmente vinculado a la Asamblea Nacional Catalana (ANC).

19 El texto en cuestión puede consultarse en www.constitucio.cat. Existe una versión en castellano a cargo de Cuesta Burguillos, D. 
más de las veces en apenas una o dos líneas, dos artículos destacan incluso en su apariencia formal por su extremo casuismo, al tiempo que otras dos cuestiones fundamentales quedan de todo punto preteridas. Nos referimos, en cuanto a lo primero, a los arts. 10, dedicado a la perspectiva de género, y 17, consagrado a la participación, cuyas abigarradas líneas consagran en un caso la igualdad de oportunidades entre mujeres y hombres, la no discriminación por motivo de embarazo o maternidad, la desaparición de la disparidad retributiva, la conciliación entre la vida profesional y familiar, la erradicación de la violencia contra las mujeres y del sexismo, la valoración del trabajo doméstico y su reparto equitativo y el derecho de la mujer a disponer de su propio cuerpo y de su salud reproductiva y sexual; y en el otro, el derecho de los ciudadanos a participar en los asuntos públicos mediante el voto, a instar la convocatoria de referendos, a promover iniciativas legislativas populares, a acceder a funciones y cargos públicos en condiciones de igualdad, a participar en la toma de decisiones referentes a las prioridades en gasto público, y a ser informados de forma transparente y veraz sobre los asuntos del Estado. Por el contrario, el Proyecto Vidal-Aparicio se desentiende casi por entero de los derechos sociales y laborales —en él no se usan ni en una sola ocasión las palabras «vivienda», «huelga», «desempleo», «seguridad social» o «jubilación», y solo se habla de «trabajo», «familia» y «salud» a la hora de regular los derechos de la mujer, y de «sindicatos» a la hora de prohibir la pertenencia a los mismos de jueces y fiscales - y, de manera aun más llamativa, pasa de largo por la decisiva cuestión de la nacionalidad, al limitarse a establecer en el artículo 11 que «la nacionalidad catalana puede ser adquirida o perdida según lo que establece la Ley», carencias ambas que resultan si cabe más llamativas en una situación social y política como la actual.

Por lo que hace al sistema de gobierno - que el artículo 2.1 ya anticipa al declarar que «La forma política de organización del Estado es la república parlamentaria»-, el Proyecto Vidal contempla (art. 28) un Parlament unicameral, no susceptible de ser anticipadamente disuelto (art. 34), formado por entre $145 \mathrm{y}$ 245 miembros, elegibles por un sistema mayoritario a una sola vuelta en circunscripciones uninominales, con la condición — de efectividad incierta- de que cada comarca habrá de contar con al menos tres circunscripciones, y la previsión — de aplicabilidad si cabe más incierta — de que «cada diputado responde de forma preferente a los intereses de los ciudadanos de la circunscripción electoral por la que ha sido escogido, y solo en segunda instancia a los intereses de su partido» (art. 29); un President de la Generalitat dotado de la doble función de ser el Jefe del Estado y también el Jefe del Gobierno, popularmente elegible (art. 36) pero susceptible de ser desposeído de su mandato tanto por aprobación de una moción de censura o la denegación de una cuestión de confianza, como por condena penal firme que le inhabilite para el ejercicio de cargos públicos —extremo este último de consecuencias imprevisibles, al no incluir la Constitución un listado de los delitos susceptibles de justificar la inhabilitación, y colocar exclusivamente en manos del Tribunal Supremo la apreciación de su comisión- (art. 36), 
y provisto de derecho a veto sobre las leyes aprobadas por el Parlament; un Conseller Primer nombrado por el President, sin que sea menester contar para ello con el visto bueno del Parlament (art. 37), llamado a conformar, pero no parece que también a liderar al gobierno; un Govern, caracterizado como «el órgano superior colegiado que dirige la acción política y la Administración de la Generalitat» y a ejercer la función ejecutiva y la potestad reglamentaria; un sistema de gobiernos locales sostenido sobre los dos únicos pilares — «aparte de las establecidas en este artículo, no hay otra agrupación o división de territorio que tenga efectos legales ni administrativos», reza el artículo 24.4- de los municipios y las comarcas; un Consejo General del Poder Judicial integrado por entre once y quince miembros, sobre cuyo sistema de elección el Proyecto calla por completo (art. 55); y un Tribunal Constitucional formado por diez miembros nombrados por el Consejo General del Poder Judicial — dos de ellos a propuesta del Govern y otros cuatro a propuesta del Parlament - entre juristas de reconocido prestigio y de trayectoria profesional contrastada, para un mandato de ocho años, renovable por mitades (art. 60), pero dotado de competencias muy limitadas como consecuencia de la restrictiva regulación de la legitimación activa para la interposición de recursos ante el mismo recogida en el artículo 59.

Por lo demás, el Proyecto Vidal-Aparicio se alinea entre los partidarios de un buen entendimiento con España, lo que se concreta de una parte en el reconocimiento del castellano como lengua cooficial «en virtud del dinamismo del que goza en nuestro país», e incluso en la aceptación de la conveniencia de promover su conocimiento entre la población, y de permitir su uso en la esfera de la administración del Estado «sin discriminación alguna» (art. 4); y de otra en la renuncia expresa a modificar sus actuales límites territoriales, «pese a que reconoce los especiales vínculos con las tierras de habla catalana bajo soberanía de otros países», en clara referencia a la Comunidad Valenciana, las Islas Baleares, el Rosellón y el Alguer. Mientras que en lo tocante a la cuestión de la defensa de Cataluña, se encuadra entre los proyectos partidarios de que Cataluña disponga «de unas fuerzas armadas adecuadas a lo que la obligan los tratados internacionales y proporcionadas con la situación geopolítica que la rodea para la defensa del territorio», si bien declara prohibida la utilización «de armas nucleares, biológicas y químicas, así como las armas destinadas a matar indiscriminadamente y todas las prohibidas por tratados internacionales», sujeta cualquier otro gasto en armamento a la aprobación del Parlamento; y «prohíbe expresamente la participación de las fuerzas armadas fuera de las fronteras del Estado, excepto en misiones humanitarias concretas o bajo mandato de la ONU cuando convenga» (art. 22).

En suma, y pese a algunas de las carencias señaladas, estamos ante un texto razonablemente completo y bien escrito, equidistante del hiperreglamentismo de unos y de la peligrosa concisión de otros, y ayuno también de los defectos de forma y sistemática que han restado seriedad a no pocas de las propuestas que estamos analizando, y que además cuenta con el valor añadido de unas cláusulas transitorias llamadas a vertebrar su puesta en marcha que se hallan ausentes - 
con ese grado de detalle- en todos los demás textos. Aun así, la idea de un presidente popularmente elegible pero censurable por el Parlamento $-\mathrm{y}$, no lo olvidemos, también por el Tribunal Supremo-; de un Gobierno irresponsable ante el legislativo; de un sistema electoral netamente mayoritario; de un Consejo General del Poder Judicial de extracción ignota; y de un Tribunal Constitucional cerrado en banda a las minorías suscita demasiadas dudas sobre su efectiva capacidad para dar a Cataluña un sistema de gobierno que sea como mínimo más sensato del que en la actualidad posee. Por más que ninguna de esas carencias ayude a explicar la verdadera razón de la menor proyección pública de este proyecto en relación con la casi simultánea iniciativa del ex juez Santiago Vidal.

\section{El Proyecto Vidal}

Sin duda alguna el presentado en enero de 2015 por el ex juez Santiago Vidal i Marsal ${ }^{20}$ ha venido siendo, de todos los proyectos constitucionales para una hipotética Cataluña independiente, el que mayor proyección pública ha logrado alcanzar $^{21}$.

Gestado merced al concurso de un nutrido grupo de colaboradores ${ }^{22}$ pero sin el patrocinio oficial de ninguna fuerza política ni mediando encargo de ninguna institución autonómica — «un trabajo de creación intelectual entre amigos», «estrictamente técnico» y «sin ninguna intencionalidad política» serían las palabras utilizadas por su principal autor para describirlo- ${ }^{23}$ el Proyecto Vidal fue presentado desde el primer momento con la pretensión de ser, si no el texto definitivo, sí al menos el embrión de una futura Constitución para Cataluña.

20 Juez de carrera y profesor de Derecho Penal y Criminología en la Universidad Autónoma de Barcelona, Vidal es también autor de varias monografías a la vez sobre temas de Derecho penal (Los tribunales de justicia durante el franquismo, 2006, y Tortura y maltratos policiales: función y control de los tribunales, 2007) y sobre la cuestión lingüística en la administración de justicia (El idioma catalán en la Justicia, 1997 y Cooficialidad lingüística en el mundo de la justicia, 2001). Siendo Magistrado de la Audiencia Provincial de Barcelona, fue sancionado por el Consejo General del Poder Judicial con tres años de suspensión por haber llevado a cabo la gestación del presente texto. Con posterioridad a ello fue contratado como asesor por la Generalitat de Catalunya, y en las elecciones del 20 de diciembre de 2015 fue elegido senador en la candidatura de Esquerra Republicana.

21 Véase, a título de ejemplo, Segura, C.: «Els carros davant els bous», El País de 31.01.2015; «La Constitución catalana del juez Vidal plantea prohibir las mayorías absolutas», $A B C$ de 31.01.2015, «Santiago Vidal propone Catalunya con listas abiertas, límite de mandatos y sin ejército», La Vanguardia de 27.01.2016; o «Santiago Vidal presenta l'esbós d'una constitució catalana que planteja prohibir majories absolutes», El Periódico de 31.01.2015.

22 En concreto - y según el testimonio del propio Vidal- J.M. Miquel, M. Aragó, S. Sardiner, J. Domingo, A. Carles, E. Ferran, J. Fonollosa, M. Llobet y F. Richarte. «En total, un grupo de diez personas que somos las que redactamos la propuesta [...] La nuestra es, pues, una Constitución que tiene padres y madres, la española sólo tenía padres» (VIDAL, S. [con Llansana, M.]: Una Constitució per a Catalunya, Pagès, Editors, 2015, p. 15).

23 Véase SuÁrez, G.: «El juez sobre patines de la Constitución catalana», El Mundo de 25.05.2014 y «El juez Vidal ve legal la redacción de una Constitución catalana», El País, de 01.05.2015. 
Se trata de un documento relativamente breve -96 artículos, vertebrados en torno a cinco títulos, de los que los cuatro primeros llevan por título respectivamente «Disposiciones generales», «Derechos y deberes», «Organización territorial y Administración pública», y «Relaciones exteriores» y el quinto carece de encabezamiento $-{ }^{24}$ cuya redacción llama poderosamente la atención por una simpleza en los fines y una pobreza en las forma ${ }^{25}$ que — de ser otras las circunstancias- habría suscitando más hilaridad que indignación entre quienes no compartieran sus fines, y más lástima que alborozo entre quienes en cambio los secundaran, y que hace si cabe más incomprensible tanto su notoria proyección pública como la súbita elevación de su principal promotor a la categoría de icono del nacionalismo.

De todos los dislates del Proyecto Vidal, seguramente los menos graves sean los que se derivan de una redacción apresurada y poco meditada, puesta en evidencia por sus abundantes erratas, su equivocada sistemática, y la deficiente presentación formal de su propuesta. La referencia contenida en el Preámbulo a la Declaración Universal de Derechos Humanos, rebautizándola como «Declaración Universal de Naciones Unidas»; el error que se desliza en el artículo 35 cuando, al describir los límites geográficos y políticos de Cataluña se olvida de que además de limitar «al norte con Francia, y al sur y al oeste con España», ésta linda también con el Principado de Andorra; la desacertada inclusión en la Sección II del Capítulo II, del Título III, dedicada al «El Poder Ejecutivo», de los artículos en los que se regula el Defensor del Pueblo y la Sindicatura de Cuentas - popularmente elegible el uno, y de designación parlamentaria el otro-, o incluso de las corporaciones locales; o la inclusión de los artículos reguladores del sistema socioeconómico de Cataluña (art. 86) y de la moneda (art. 89) en el título dedicado a las «Relaciones Exteriores»; la caótica regulación del modelo de organización territorial de la futura República catalana, repartida entre el artículo 36, por el que se introducen las comarcas y las veguerías, el 57, dedicado al desarrollo local, los arts. 64 a 66, consagrados de nuevo a municipios y veguerías, y los arts. 67 a 69 al Valle de Arán; o —en fin- la cláusula contenida en el artículo 90, donde se pone de manifiesto el deseo de Cataluña de «seguir formando parte de la Unión Europea y pasar a ser lo más rápidamente posible su estado número 29», olvidándose de que con media docena de candidatos en la vía de la adhesión, y otros varios más postulándose para ello, la más optimista de las perspectivas sería la que le permitiera convertirse en el socio treinta y muchos de la

24 El texto en cuestión puede consultarse www.unanovaconstitucio.cat. Hay versiones en catalán, castellano, aranés, inglés, francés e italiano.

25 «Candoroso en extremo (un ingenuo catálogo de buenas intenciones)» es la valoración que hace de él J.B. Culla i Clarà («De casos y jueces», El País de 06.03.2015) antes de manifestar que con algunos puntos concretos su desacuerdo es «total»; en tanto que para E. Fossas EsPaDALER («El extraño caso del juez constituyente», El País de 28.02.2015) el Proyecto Vidal constituye «una broma o quizá de una 'práctica' realizada por algún alumno de primero de Derecho», plagada de «errores, despropósitos y disparates [...] muy útiles para explicar a los estudiantes los rudimentos de la teoría constitucional». 
Unión, son solo unos pocos pero ilustrativos ejemplos de un texto que se adivina hecho con excesivo apresuramiento.

Algo más serias son ya las objeciones que se derivan de un más que precario dominio de las categorías más corrientes del Derecho constitucional como el que salta a la luz en un varias de sus disposiciones. Como la del artículo 2.1, en el que se afirma que Cataluña será una «república parlamentaria unicameral y no presidencialista ${ }^{26}$, como si «parlamentaria» y "presidencialista" no fueran de suyo términos antitéticos; o la del 2.2, que convierte a «la cultura» en un "principio» del ordenamiento jurídico del Estado; o la del artículo 15, en el que - después de haber vetado de manera expresa el uso del velo islámico ya en otro lugar de la Constitución (art. 13.3) — se establece sin más que «nadie podrá llevar el rostro cubierto en su totalidad, a fin de evitar la impunidad», seguramente sin reparar que esa doble referencia y esa coma en el enunciado desligan el ocultamiento del rostro de su finalidad religiosa y de su intencionalidad delictiva y en consecuencia coloca fuera de la Constitución manifestaciones festivas tradicionales como los carnavales o las procesiones de Semana Santa; o la que denota o la que deriva de la muy precaria regulación de la futura «Sala de Garanties Constitucionals», a la que se encomienda (art. 81) la resolución de los recursos de inconstitucionalidad y de amparo, especificando quienes estarán legitimados para interponer los segundos, pero soslayando esta capital cuestión en el caso de los primeros; o - conectando con lo anterior- la que hallamos en el artículo 95.2, que prohíbe a partidos, instituciones o particulares interponer recursos de inconstitucionalidad contra los proyectos de reforma constitucional ...cuando el 95.1 acababa de prohibir a la Sala de Garanties Constitucionals revisar de oficio o a instancia de parte estas mismas reformas constitucionales, que por otra parte, y por su propia naturaleza, nunca son objeto de control de constitucionalidad.

Con todo, las cláusulas más alarmantes del proyecto constitucional de Vidal y sus colaboradores son en realidad aquellas que dejan al descubierto la peligrosa combinación entre su cándida visión de la vida política y su escaso conocimiento del Derecho europeo y comparado ${ }^{27}$. Disposiciones como la del artículo 12.3, que proclama que «los catalanes seguirán siendo ciudadanos europeos con todos los derechos y deberes de que disfruten en el momento de constituirse la República catalana» a pesar de que el Tratado de la Unión Europea establece con claridad

26 Nótese que, a diferencia de los proyectos de Reagrupament y de Joan Fonollosa, ímplicitamente republicanos, el de Santiago Vidal — como también el de Vidal-Aparicio— son expresamente republicanos, de modo que las referencias que en aquellos se hacen al «Catalunya» son hechas aquí a la «República de Catalunya» o a la «República catalana».

27 Valoración ésta que obliga a poner en duda la alegre afirmación de su autor en el sentido de que «hicimos un trabajo previo de investigación de modelos constitucionales en los que nos queríamos reflejar. Enseguida acordamos que haríamos una mezcla del texto del sistema constitucional nórdico — Suecia, Dinamarca, Noruega, Islandia, etc-, el sistema anglosajón [...] e incorporando aspectos del Derecho occidental de Alemania y Suiza, porque al fin y al cabo somos un país mediterráneo» (VIDAL, S. [con LlanSANA, M.]: Una Constitució..., cit., p. 16). 
que solo son ciudadanos de la Unión quienes lo son de sus Estados miembros, y esa no es una cuestión susceptible de resolverse mediante una decisión unilateral, siquiera de rango constitucional. O como la del artículo 42.1, que establece que para el procesamiento de los diputados «será competente el/la juez/a natural predeterminado por la ley, previa autorización de la Sala Penal del Tribunal Supremo de la República, único órgano con competencia para levantar la inmunidad parlamentaria en caso de delito», cuando con carácter previo el artículo 7.1 había declara el aforamiento «un privilegio inadmisible en un Estado democrático de Derecho». O como las contenidas en los arts. 39 y 41, en los que se pergeña el sistema electoral del futuro Estado catalán. Además de que lo que de él trascendió en su día ante la opinión pública — que, al objeto de evitar los abusos de poder, el partido que ganara las elecciones nunca podría hacerse con más del 49\% de los escaños- constituye un injustificable atentado contra la soberanía popular - ¿por qué si los ciudadanos decidieran votar masivamente a un partido, éste se habría de ver privado de una mayoría parlamentaria igualmente amplia? - amén de una cláusula de efectos potencialmente perversos — si el partido vencedor nunca podría tener más del $49 \%$ de los escaños, resulta forzoso concluir que en un contexto de bipartidismo neto el partido derrotado habría de hacerse icon el $51 \%$ de los mismos! - lo cierto es que los restantes elementos del sistema electoral diseñado por Vidal no resultan menos disparatados, toda vez que se establece que el sistema electoral será proporcional, y que operará con «listas abiertas», pero al mismo tiempo se crean 41 circunscripciones para el reparto de apenas 105 escaños, con la inevitable consecuencia de que más de la mitad de ellas serán uninominales y, en consecuencia, operarán bajo un criterio mayoritario y sin listas de ningún tipo. Aunque más absurdo todavía sea quizás establecer en el artículo 51 la elegibilidad por sufragio universal del Presidente, «Jefe del Estado y máxima autoridad de Cataluña», para contemplar en el que le sigue la posibilidad de su cese mediante una moción de censura del Parlamento, mecanismo éste al que en cambio no está sometido el Primer Ministro, cuya designación y cese, al más puro estilo del constitucionalismo decimonónico, corresponde en exclusiva al Jefe del Estado sin que al parlamento le quepa al respecto competencia alguna. O, en fin, que se contemple la revocación de los cargos públicos electos (art. 24) ${ }^{28}$, cuando es sabido que se trata de una fórmula incompatible con el uso de un sistema electoral proporcional, toda vez que permite a las mayorías quitarse de encima a los

28 Según esta disposición, los electores podrán solicitar de los tribunales de justicia la celebración de referéndums revocatorios de alcaldes, concejales y diputados «que incumplan sistemáticamente su programa electoral», siempre que la petición cuente con el aval de «al menos el $25 \%$ de los electores de la lista votada». Al margen de la absoluta imposibilidad de comprobar si los solicitantes de la revocación son quienes en efecto votaron al cargo público electo al que se quiere desposeer de su mandato - y no quienes lo hicieron por cualquiera de sus contrincantes-, constituye una incógnita si del tribunal de justicia competente se espera que lleve a cabo una vista oral al objeto de dilucidar si ha existido o no incumplimiento programático, y en tal caso cual debería ser el procedimiento a seguir, cuáles los medios de prueba ...y cuáles — si alguna— las eximentes completas o incompletas susceptible de aplicarse. 
representantes de las minorías apelando al incumplimiento de un programa electoral por el que ni siquiera sería preciso que hubieran votado.

Un último conjunto de disposiciones del Proyecto Vidal merita, en cambio, una valoración un tanto más positiva. Se trata de aquéllas que abordan de manera explícita o implícita las relaciones entre la hipotética República de Cataluña y España. En una línea similar a la del Proyecto Vidal-Aparicio, pero en claro contraste con las cláusulas recogidas en otros textos caracterizados por una neta voluntad expansionista - $\mathrm{O}$ al menos intrusiva - en relación a los territorios de habla catalana que tras una eventual ruptura de Cataluña seguirían formando parte de España, Francia o Italia, el artículo 35 del Proyecto Vidal renuncia a la utópica construcción unos Països Catalans al sostener que Cataluña «se compromete a mantener los actuales límites territoriales, sin perjuicio de fomentar los especiales vínculos con las tierras de habla catalana bajo soberanía de otros Estados», disposición que se complementa con las del 81.1 y 2, en virtud de los cuales Cataluña de declara «consciente de los múltiples lazos que en el transcurso de nuestra historia ha tenido con el pueblo español, y desea firmemente mantenerlos y mejorarlos en condiciones de bilateralidad», y se compromete a "garantizar los derechos de todos aquellos catalanes que, por una u otra razón, quieran libre y democráticamente conservar sus relaciones personales y colectivas con nuestros hermanos de la península ibérica». En idéntico sentido, y nuevamente en claro contraste con las disposiciones en materia lingüística de otros proyectos, radicalmente partidarios del monolingüismo, el artículo 4 del Proyecto Vidal hace gala de un notable pragmatismo a este respecto al afirmar que, sin perjuicio de la consideración del catalán como lengua oficial, propia y preferente de Cataluña, «dada la composición demográfica y social actual de Cataluña, y con la explícita voluntad de velar por la mejor convivencia entre todos los catalanes, sea cual sea su origen, el castellano goza del estatus de lengua cooficial, y podrá ser empleado oralmente y por escrito para todos aquellos ciudadanos que así lo deseen».

Sea como sea, es forzoso concluir que el proyecto Vidal es un texto técnicamente defectuoso, de aplicabilidad altamente problemática, cuya redacción obliga a recordar que si una buena constitución no es susceptible por si sola de solucionar los problemas de un país, un mal texto constitucional, en cambio, sí es suficiente para sumir en el caos a quien trate de gobernarse según sus reglas. Así las cosas, no puede sino merecer una última valoración positiva la voluntad de los promotores de este proyecto de abrirlo a las sugerencias de los ciudadanos interesados, permitiendo la presentación de enmiendas al objeto de proceder a su estudio y hacer pública una segunda versión, teóricamente mejorada, del mismo. En todo caso, el resultado de este proceso revisorio es a día de hoy, aun desconocido ${ }^{29}$.

29 Aunque a mediados de septiembre de 2015 Vidal anunció contar ya con más de 2.000 enmiendas («El jutge Vidal modifica el seu text constitucional», Diari de Girona, de 16.09.2015) quizás esté fuera de sitio esperar cambios sustanciales en el texto original, ni mucho menos una completa depuración de las deficiencias técnicas detectadas, toda vez que al parecer la inmensa mayoría de las mismas se focalizan en tres 


\section{El Proyecto Fonollosa}

Presentado (también) en el Ateneu Barcelonès el 7 de abril de 2015 bajo el encabezamiento de «Una proposta de Constitució catalana» ${ }^{30}$, el que podríamos denominar «Proyecto Fonollosa» constituye un empeño básicamente personal de Joan Fonollosa i Guardiet, consultor empresarial, ingeniero, y profesor de las Universidades Autónoma de Barcelona y Politécnica de Cataluña ${ }^{31}$, cuya virtualidad — limitada una vez más por su procedencia — cabe anticipar será escasa.

Desde una perspectiva formal, estamos ante un texto mucho más largo, completo y minucioso, y mucho mejor escrito y sistematizado que todos los analizados hasta ahora. En efecto, el Proyecto Fonollosa se halla integrado por un total de 247 artículos, precedidos de un breve preámbulo pero sin disposiciones adicionales, vertebrados a su vez en cinco títulos («Principios generales», «Las instituciones generales de Cataluña», «Las instituciones locales de Cataluña», «Elección y sustitución de cargos electivos», y «La Constitución»), subdivididos a su vez en capítulos y secciones. En abierto contraste con las numerosos lagunas detectadas en otros textos, el Proyecto Fonollosa es en cambio un texto extraordinariamente completo, en el que se regulan - es cierto que con alguna morosidad- los derechos y las libertades, pero también — esta vez con sumo detalleel sistema institucional de una hipotética Cataluña independiente, tanto a nivel de Estado como a nivel local, y en el que no se esquivan cuestiones conspicuamente ausentes en los restantes proyectos como las fuentes del Derecho, la defensa de la Constitución, la conformación del poder judicial, o el régimen local de Cataluña.

Además, es también —y con diferencia- el más original de los proyectos constitucionales barajados hasta ahora, repleto de innovaciones institucionales no siempre acertadas, pero cuando menos reveladoras de un esfuerzo intelectual estimable, explicadas las más de las veces con notable precisión y afán de garantismo. Sin embargo, se trata de un texto lastrado por la manifiesta falta de formación jurídica del autor, que se traduce en una técnica legislativa manifiestamente mejorable, en la que en ocasiones sobran las precisiones, y en otras las declaracio-

aspectos concretos del texto, como son el régimen lingüístico, la existencia o no de un Ejército catalán (el art. 85 del proyecto declara a Cataluña »territorio libre de ejército y fuerzas armadas, salvo la policía propia [Mossos d'Esquadra] encargada de la seguridad pública»), y la conveniencia de la comarcalización.

$30 \mathrm{El}$ texto en cuestión puede consultarse www.unanovaconstitucio.cat/wp-content/uploads/2015/01/Constitucio-Joan-Fonollosa.pdf

31 Iniciado en política de la mano de Lluís M. Xirinacs, Fonollosa ha militado en ERC — donde llegó a ser Conseller Nacional y Secretario del Comité Ejecutivo - entre 1983 y 1989, en Esquerra Catalana — partido del que fue Secretario del Comité Ejecutivo - entre 1989 y 1993, en CDC — donde fue Consejero Nacional y miembro del Comité Ejecutivo Nacional- entre 1993 y 2009, así como en Reagrupament Independentista y Solidaridad por la Independencia donde trató en vano de forjar una candidatura independentista conjunta para las elecciones catalanas de 2010. Además de una novela y numerosos trabajos de índole profesional, es autor de Espanya explicada als catalans, Duxelm, 2013. 
nes de intenciones carentes de consecuencias normativas, o incluso las reflexiones filosófico-políticas más propias de un manifiesto que de un texto normativo.

El texto se abre con tres alusiones a otros tantos mitos vertebradores del independentismo catalán: el del multisecular arraigo de la democracia en Cataluña en contraposición a la — no explicitada, pero intuída— supuesta tendencia hacia el caudillismo de los castellanos (Preámbulo: «Cataluña ha tenido, desde sus inicios mismos, como pilares básicos de su comportamiento colectivo la libertad, el respeto a la ley y el pacto entre iguales»), el de la lengua catalana como elemento vertebrador, y hasta definitorio, de su identidad nacional (Arts. 1.1 y 1.2: «La Nación Catalana está formada por todas las personas que tienen la voluntad de formar parte de ella. Esta voluntad se demuestra principalmente empleando de forma usual y habitual la lengua catalana») y el de la existencia de una nación catalana cuyas fronteras trascienden las de la actual comunidad autónoma de Cataluña (art. 1.3: «El territorio de la Nación Catalana abarca todas las tierras de habla catalana, de Salses a Guardamar y de Fraga hasta Mahón y Alguer»).

De esta última afirmación se deriva una primera inconsistencia. El texto se declara aplicable de manera exclusiva a Cataluña (art. 2.6), pero al mismo tiempo se aventura a afirmar que «Los diferentes territorios de la Nación Catalana se relacionan entre ellos en régimen de igualdad bajo los principios de igualdad, libertad y respeto mutuo» (art. 2.3) obviando el hecho de que ni la Comunidad Valenciana ni las Islas Baleares han hecho jamás patente su deseo de convertirse en Estados soberanos desarrollar una política internacional que no sea la común del Estado español ${ }^{32}$; proclama a la Catalunya Nord y la Franja de Ponent como «territorios históricos de Cataluña, que le han sido amputados en contra de su voluntad» y que Cataluña aspira a reintegrar algún día (art. 2.4), mientras que acepta sin objeción alguna que Principado de Andorra y la ciudad italiana de Alguer tengan «su propio régimen político» (art. 2.2); y a sensu contrario, reconoce que el Valle de Aran «es una pequeña porción de la Nación Occitana que por azares históricos se halla enclavada dentro de los territorios regidos por las Instituciones de Cataluña» y le reconoce tanto el derecho de separarse de Cataluña como el de mantenerse en su seno merced a un estatuto paccionado (art. 4).

Por su parte, la centralidad de la identidad lingüística a la hora de definir qué sea ser catalán tiene su correlato en la consideración del catalán como «la lengua propia de Cataluña y el eje vertebrador de la Nación catalana» (art. 6.1) y «la oficial y habitual de todas las instituciones de Cataluña» (art. 6.2), derivándose de ello el que todos los ciudadanos de Cataluña tengan «el deber de conocer-

32 Idéntica planteamiento se percibe, ahora en el plano de los símbolos, en el artículo 7, cuando tras afirmar que la bandera de Cataluña es la tradicional de las cuatro barras, se establece que dado que ésta la «es compartida con las otras tierras de la Nación Catalana y con Aragón, cuando sea usada para representar conjuntamente en Cataluña y otros territorios, Cataluña será representada en estas ocasiones por la bandera de San Jorge», de nuevo ignorando que tanto Aragón, como la Comunidad Valenciana y las Islas Baleares definieron hace ya décadas sus símbolos distintivos, que son distintos de los de Cataluña. 
la y el derecho de usarla sin limitaciones», que «sólo tendrán validez jurídica las disposiciones redactadas en lengua catalana» y que «la relación entre los ciudadanos y las instituciones de Cataluña se hará siempre y exclusivamente en lengua catalana» (art. 6.3). Ante este radical monolingüismo las posibilidades de que de manera excepcional se puedan dictar en otros idiomas «disposiciones [...] para favorecer el arraigo de los recién llegados» (art. 6.3), o de que durante el plazo de diez años a partir de la entrada en vigor de esta Constitución los ciudadanos de Cataluña se puedan relacionar también con las Instituciones de Cataluña en castellano (Disposición transitoria al art. 6) no dejan de ser concesiones menores y llamadas a tener una escasa efectividad.

En lo tocante a los derechos, el Proyecto Fonollosa es - ya lo hemos insinuado- altamente deficiente. De entrada, el grueso de los artículos incluidos en el Capítulo Tercero, intitulado «Derechos y deberes» se halla consagrado a definir el régimen de la nacionalidad, a determinar la mayoría de edad ${ }^{33}$, y a regular el estatuto de los extranjeros, la extradición y el asilo, de modo que en puridad los artículos dedicados a enumerar y garantizar los derechos fundamentales de los catalanes quedan reducidos a poco más de media docena, redactados además en un tono tan insustancial como el del artículo 22.1, que proclama que «los límites de la libertad de cada uno corresponden a los de la libertad de los demás» o el del 22.1 y 2 , que nos recuerda que «el uso de la libertad no exime de la responsabilidad por sus consecuencias» y que «todo el mundo es responsable de las consecuencias de sus actos y debe responder ante la ley o de las otras personas que hayan sido perjudicadas». Semejante carencia, tan grave como inexplicable, trata de ser paliada con la remisión a una Carta de Derechos y Deberes que «complementará y detallará los establecidos por la Constitución y los mantendrá permanentemente adaptados al los usos y costumbres vigentes en cada momento» y cuyas disposiciones «son parte integrante de la Constitución», en lo que constituye una solución altamente insatisfactoria ${ }^{34}$.

33 En este caso de una manera cuando menos pintoresca: el artículo 17.2 establece que «la mayoría de edad se adquiere a los dieciocho años», el 17.3, que «la ley preverá la progresiva adquisición de derechos y deberes a partir de los catorce años», y por fin el 17.4 que «en particular, los jóvenes con catorce años cumplidos tendrán el derecho de sufragio activo pero no pasivo. Este sufragio se hará en una urna separada, llamada urna joven, el resultado de la cual se dividirá por dos antes de sumarse al resto de votos en el escrutinio».

34 Aunque el recurso a regular los derechos y las libertades en una carta separada de la constitución no es novedosa - ya lo hicieron los padres fundadores de los Estados Unidos, los constituyentes franceses de 1958 o los checos de 1992- y puede ser inobjetable jurídicamente, comporta una innegable minusvaloración de los derechos en relación con el resto de las disposiciones constitucionales, que históricamente solo se ha justificado en momentos en los que era urgente adoptar una constitución, pero resultaba imposible alcanzar un acuerdo en esa materia, circunstancias que evidentemente no se dan en el caso catalán. Por lo demás, es todavía más preocupante que el procedimiento para la elaboración y actualización de esa Carta, esta vez sin precedentes, encomiende su redacción al Sindic de Greuges y su aprobación «sin modificaciones» y por una mayoría de dos tercios al legislativo (art. 24.3). Idéntico procedimiento se contempla para la elaboración y actualización de la Carta Electoral —el equivalente a la Ley Electoral en otros ordenamientos_-, con la salvedad de que su redacción corre en este caso de cargo del Síndic Notari (art. 212.3). 
En lo tocante al sistema institucional «general», recogido en el Título Segundo, el Proyecto Fonollosa comienza introduciendo un órgano de nueva creación y de difícil catalogación, pese a que su denominación cuente ya con siglos de historia: «Les Corts de Catalunya». Lejos de tratarse de una nueva — vieja, en realidad - forma de referirse al actual Parlament, se trata de una institución enteramente distinta, a la que se caracteriza como «la máxima representación del pueblo de Cataluña» (art. 34), se le encomienda «la alta misión de supervisar el funcionamiento de todas las otras instituciones de Cataluña y de establecer las líneas más generales a seguir» (art. 35), y se la integra mediante la agregación de tres «brazos»: el «parlamentario», integrado por todos los diputados del Parlament de Cataluya; el «institucional», vertebrado a su vez en distintas «manos» e integrado por el President y los ex Presidents de la Generalitat, los ex Presidentes del Parlament y del Tribunal Supremo, los magistrados de éste órgano, y los Sindics y ex Sindics y Fiscales y ex fiscales Generales; y el «local» integrado por todos los batlles y vegers de Cataluña, y por los alcaldes de las principales poblaciones en número suficiente para sumar junto con los anteriores los dos tercios de Les Corts (art. 36). Pese a la aparatosidad de su composición, estructura y sistema organizativo, a la postre el proyecto encomienda a estas Corts funciones no muy distintas de las que en otros órdenes constitucionales se encomiendan al parlamento, entre las que se cuentan la recepción de cuentas por parte de otros órganos constitucionales, el nombramiento de altos cargos, la adopción de declaraciones y de decisiones «que obligan a todas las instituciones de Cataluña, con fuerza de ley», o la celebración de «sesiones de honor» a los efectos de rendir homenaje a personas o instituciones, catalanas o extranjeras. De modo que su mera existencia brinda un potencial de conflicto con las atribuciones del propio Parlament, si cabe más agudo desde el momento en que las decisiones de Les Corts de Catalunya están llamadas a adoptarse no por mayoría de sus miembros, sino merced al voto separado de cada brazo (art. 39).

En menor medida, llama también la atención la introducción, igualmente novedosa en nuestro constitucionalismo, de la llamada Sindicatura, definida (art. 126) como «la reunión de tres órganos unipersonales emanados de les Corts de Catalunya, llamados Síndic de Greuges, Sindic de Comptes y Sindic Notari, y los servicios administrativos que comparten», a los que se dota de un mandato (siete años), un estatus, y unas competencias muy superiores a la que son habituales en órganos análogos.

Por lo que respecta al resto de las instituciones catalanas, quizás lo mas reseñable sea que el proyecto contemple un ejecutivo monista, en el que el President de la Generalitat, de elección popular por ballotage, sería a la vez Jefe del Estado (art. 57) y cabeza del Ejecutivo (art. 59) ${ }^{35}$; un gobierno susceptible de

35 Aunque seguramente el aspecto más chocante de la regulación de esta figura sea la posibilidad de que pase a ostentar el título de Conde de Barcelona (art. 58), son otras las cuestiones que meritan una reflexión 
ser coordinado — bajo la alta dirección del President- por un «Conseller Primer» y uno o varios «Conseller Destacats» (art. 64); un Parlament provisto de capacidad legislativa, presupuestaria y de control, pero subordinado a la autoridad «del pueblo de Cataluña expresada en referéndum vinculante y a las decisiones de Les Corts de Catalunya» (arts. 70.1 y 2), integrado a partes iguales por «diputados territoriales» —elegibles cada cinco años por un sistema mayoritario en circunscripciones uninominales, a razón de uno por cada cien mil electores-y por «diputados generales» —elegibles cada cuatro años, por un sistema proporcional y en circunscripción electoral única-cuya renovación escalonada convierten a la cámara en «una continuidad indefinida en el tiempo»; un sistema de autogobierno local vertebrado en tres niveles - ajuntaments, batllies y vegueries - (art. 152), dotado cada uno de ellos con su propio sistema institucional, y en el que también cabe la posibilidad de conformar mancomunidades (art. 154); y un poder judicial encabezado por un Tribunal Suprem de Catalunya que sería a la vez última instancia jurisdiccional (art. 118) y garante de la constitucionalidad de las normas (art. 70) ${ }^{36}$.

Por último, el Proyecto Fonollosa llama también la atención por la rotundidad de su apuesta por la participación ciudadana que no solo se concreta en la elegibilidad popular de Presidente, alcaldes, concejales, batlles, veguers, y diputados, sino también en la generalización de procedimientos de revocación para todos los cargos unipersonales de elección mayoritaria (arts. 234 y 235), y en una regulación del referéndum en términos notablemente generosos (arts. 145 a 151). Desafortunadamente, esa radicalidad en su apuesta por la democracia participativa lleva en ocasiones al autor a proponer fórmulas tan disparatadas como la del artículo 213.3, en virtud del cual los compromisos electorales adquiridos durante la campaña de forma pública, notoria o reiterada serán vinculantes para los candidatos y hasta exigibles por sus electores ante los tribunales de justicia, debiendo la ley electoral contemplar las sanciones e indemnizaciones correspondientes, que serán especialmente graves en el caso de «promesas hechas sabiendo que no se podrían cumplir»; o la del artículo 223 , que ordena dejar vacantes los

más seria. La primera, es que el President posee un limitado (solo tres veces por cada mandato), pero significativo (solo superable por una mayoría de dos tercios) derecho de veto sobre las leyes aprobadas por el Parlament (art. 99); y la segunda es que no puede ser relevado de su cargo por el Parlament (ya que el 107 no menciona la moción de censura entre las formas de responsabilidad a que está sujeto el President, y cuando el artículo 240 refiere los efectos de las mociones de reprobación y de confianza, especifica que son solo «la expresión formal del grado de satisfacción o insatisfacción del órgano competente sobre la gestión del afectado», y que «no producen efecto jurídico alguno»), lo que unido a su elegibilidad popular decanta el régimen político de Cataluña hacia el presidencialismo.

36 O tal vez no: el artículo 70.3 establece que «Si el Tribunal Supremo sentencia que algún aspecto de las leyes es contrario a la Constitución, el Parlamento está obligado a modificarla o poner en marcha un proceso de reforma constitucional», lo que equivale a decir que el Tribunal Supremo carece de un efectivo poder de control de la constitucionalidad de las normas, no cabiéndole otra posibilidad que la de instar el Parlamento a proceder a su reforma. El proyecto constitucional evita responder que sucedería en caso de que el Parlamento — autor, obvio es decirlo, de la norma inconstitucional— se negara a hacerlo. 
escaños del Parlamento que idealmente deberían corresponder a los votos emitidos en blanco, entendiendo «que sus ocupantes estarán siempre presentes y se abstendrán en todas las votaciones», y poniendo la subvención pública que a éstos debería corresponder «a disposición del Síndic de Comptes que la destinará obligatoriamente a aminorar la deuda pública».

En suma, estamos ante un proyecto sumamente trabajado que, a diferencia de otros, aparenta ser fruto de una intensa reflexión y aporta novedades interesantes y potencialmente útiles, pero al que lastra su exceso de reglamentismo, su pobre técnica legislativa, su irreflexivo utopismo y —reiterémoslo- su nula representatividad política.

\section{LA CUESTIÓN DE LAS FORMAS}

Aunque alguno de los proyectos constitucionales que acabamos de analizar ha incluido cláusulas relativas al modo en que debería llevarse a cabo su adopción por parte de las instituciones catalanas competentes - bien sean las actualmente existentes, o las que a tal efecto fueran a crearse en el futuro-, no ha sido así en todos los casos. Mientras que, por otro lado, en los últimos meses se han hecho públicas propuestas de muy diverso tipo respecto de cómo debería articularse el proceso que llevara a la adopción de una futura constitución para Cataluña, con abstracción de cual fuera a ser el contenido último de ésta. Diríase, pues, que al tiempo que ha venido siendo detectable una creciente preocupación por los resultados, también ha crecido la preocupación por las formas o los procedimientos.

El punto de inflexión de este debate podría muy bien situarse en la «Moció 157/X del Parlament de Catalunya, sobre el 9 de novembre i l'obertura d'un procés constituent», de (13 de noviembre de 2014) $)^{37}$, por el que se instó al Gobierno catalán «a encargar $[\ldots .$.$] a un grupo de trabajo designado de forma conjunta por el Par-$ lamento mismo y por agentes políticos y sociales representativos de la pluralidad del tejido existente, la redacción del procedimiento democrático y participativo que habrá der regir el proceso constituyente. El diseño de este proceso participativo, que tendrá en cuenta los trabajos del Consell Assessor para la Transició Nacional, incluirá los mecanismos, las condiciones, el formato y los tiempos, espacios y procedimientos de debate y decisión populares sobre la redacción de unas nuevas bases constituyentes de la futura República, si esta fuera la voluntad mayoritaria de los catalanes».

La referencia contenida en el acuerdo a los trabajos del Consell Assessor para la Transició Nacional —el órgano creado en febrero de 2013 por la Generalitat de Catalunya al objeto de analizar los diferentes factores a tener en cuenta en el proceso

37 Butlletí Oficial del Parlament de Catalunya n. ${ }^{\circ}$ 429, de 17 de noviembre de 2014, p. 18 (disponible en línea en www.parlament.cat). 
de transición hacia un estado independiente — traía causa de la previa publicación por parte de este consejo de su Informe n. ${ }^{\circ}$ 10, fechado el 14 de julio de 2014, intitulado «El procés constituent», y encaminado a «analizar el proceso que habría que abrir en Cataluña en caso de constituirse en estado propio e independiente, para su plena institucionalización ${ }^{38}$. Dejando de lado las consideraciones del Consejo sobre lo que denomina «La fase previa al proceso constituyente: la creación del nuevo Estado», que el documento aborda por su íntima conexión con «El proceso constituyente en sentido estricto», en relación con este último la propuesta del Consejo arranca abogando por la conveniencia de que no bien se halla procedido a la proclamación de la independencia de Cataluña - y en su caso a su ratificación en referéndum - el Parlament de Catalunya redacte una ley sobre el proceso constituyente, al objeto tanto de regular los pasos a seguir como de establecer un régimen provisional de gobierno, en el que deberían contemplarse cuando menos las cuestiones relativas a los derechos y libertades de las personas, la nacionalidad y el régimen lingüístico del nuevo Estado; ley que «por su función y su contenido, actuaría a modo de Constitución provisional y podría presentarse como una ley constitucional provisional», que idealmente debería ser aprobada con una mayoría lo más amplia posible, y no tendría por qué ser particularmente exhaustiva en su regulación. A partir de ahí, y en los términos de esa ley del Parlamento, el proceso constituyente que se abriera debería desarrollarse «de acuerdo con estándares democráticos altamente exigentes», y comprender al menos (1) unas elecciones constituyentes, «que se podrían obviar solo en el caso de que las elecciones celebradas en clave plebiscitaria se hubieran celebrado muy poco tiempo antes de esta proclamación [de la independencia]»; (2) una fase de iniciativa constitucional, «que sería recomendable que se atribuye al propio Parlamento, mediante la creación de una ponencia conjunta de todos los grupos parlamentarios»; (3) una fase de tramitación y de aprobación parlamentarias, en la que habría que valorar la posibilidad de requerir para su aprobación una mayoría cualificada (nunca más rigurosa que la mayoría absoluta, puntualiza el documento), «con el fin de favorecer el consenso en torno a la norma fundamental» y en la que (4) deberían articularse fórmulas de participación ciudadana, en forma de audiencias parlamentarias, participación a través de medios telemáticos y otros; y, por último (5) y un referéndum de ratificación por parte de la ciudadanía en el que - puntualiza de nuevo el documento- «como es habitual en los referéndums de este tipo, no resultaría exigible ningún tipo de quórum ni de mayoría especiales».

Paralelamente, también desde Procés Constituent —el movimiento social puesto en marcha en abril de 2013 por el economista A. Oliveres y la monja T. Forcades $^{39}$, más tarde integrado en la candidatura Barcelona en Comú- se había

38 Consell Assessor per a la Transició Nacional: El procés constituent, Generalitat de Catalunya/CATN, Barcelona, 2014.

39 Vid. Manifest per la convocatoria d'un Procés Constituent a Catalunya (en línea en wuw.procesconstituent.cat).

UNED. Teoría y Realidad Constitucional, núm. 37, 2016, pp. 405-433 
procedido a la conformación de un grupo de trabajo a fin de planear una «hoja de ruta para un proceso constituyente» cuyas primeras conclusiones vieron la luz en marzo de $2014^{40}$. Pese a no plantearse en ellas un modus operandi claro e inequívoco, de su redacción y de sus contínuas alusiones a procesos recientes en América Latina (Venezuela, Bolivia, Ecuador) y Europa (Islandia) cabría deducir su apuesta por un proceso constituyente altamente participativo y de corte asambleario, verificado en el seno de un parlamento operando bajo fuerte presión social, y llamado no solo a crear las instituciones gubernamentales necesarias para materializar la independencia de Cataluña, sino también a transformar por entero el modelo económico y social del país.

Con posterioridad a la resolución del Parlament, y a la espera de un acuerdo gestado en el modo y en los términos contemplados por ésta, en enero de 2015 el llamado Grup Promotor per a la Convenció Constitucional —una iniciativa impulsada entre otros por miembros de los grupos Procés Constituent, Constituents $15 \mathrm{M}$ y Parlament Ciutadà - avanzó a través del documento «La Convenció Constitucional. Una proposta per elaborar la constitució des de la radicalitat democrática» ${ }^{41}$ la idea de desarrollar un proceso constituyente «inclusivo de todos los sectores sociales», «que garantice las condiciones de calidad democrática en la elaboración del texto constitucional», $\mathrm{y}$ "que integre diversas perspectivas complementarias de la democracia en la elaboración de la Constitución», susceptible de materializarse en un plazo de 18 meses y de vertebrarse en cuatro fases, respectivamente etiquetadas como «fase vinculada a la democracia participativa a iniciativa de la ciudadanía activa», «fase vinculada a la democracia participativa con apoyo institucional», «fase vinculada a la democracia representativa» $\mathrm{y}$ «fase vinculada a la democracia directa». La propuesta consistiría, básicamente, en abrir el proceso constituyente poniendo en valor el debate actualmente en curso en el seno de los movimientos sociales, asociaciones ciudadanas y grupos de expertos que han avanzado ya sus propuestas constitucionales, aprovechando y reconociendo «su liderazgo pionero $[\ldots]$ garantía del origen y desarrollo radicalmente democráticos de la Convención Constitucional»; para acto seguido, y ya contando con el apoyo de las instituciones poner en marcha «debates de vocación masiva, abiertos al conjunto de la ciudadanía y representativos de la diversidad»; para a continuación trasladar los resultados de los mismos al Parlamento de Cataluña, en deliberación conjunta con «representantes de la diversidad social [seleccionados] aplicando criterios de género, edad, territorio, etc.» y contando con el asesoramiento de expertos para conseguir textos de alta calidad técnica, siempre sujetos «a un estricto procedimiento de transparencia y de rendición de cuentas»; para en última instancia, someter el texto constitucional a referéndum «como garantía de tituent.cat).

40 Vid. Ríos, V.; García V. y Mestre, S.: «Full de Ruta per un Procés Constituent», (wiki.procescons-

41 Consúltese la actividad y los planteamientos del grupo en https://twitter.com/ConvencioConst. 
que la soberanía reside en el pueblo y que éste siempre tiene la última palabra», con la particularidad en este último paso del proceso de que «para que no se pueda plantear como una opción de todo o nada, sería conveniente introducir la posibilidad de que la ciudadanía pueda expresar su apoyo, por separado, y de forma simultánea o consecutiva, a las diversas partes que componen este texto final» ${ }^{42}$.

Un conjunto de provisiones con las que Vidal-Aparicio ${ }^{43}$ se muestra solo parcialmente de acuerdo. Para el constitucionalista catalán, sería suficiente con confiar la redacción del proyecto de constitución a un comité redactor — que no debería ser excesivamente grande a fin de que fuera suficientemente agil, y que sería deseable que estuviera integrado por constitucionalistas especializados en Derecho comparado y en Sistemas Políticos Comparados- designado en su seno por un Parlamento popularmente elegido previa advertencia a los votantes de que entre sus tareas se incluiría la de redactar la constitución; someter ese proyecto a un proceso de enmienda, debate y aprobación en el seno de la cámara, en cuyo transcurso podrían activarse mecanismos de iniciativa popular que permitieran la toma en consideración de enmiendas presentadas por grupos e individuos no representados en el parlamenteo; y concluirlo con la ratificación popular del proyecto en un referéndum en el que - ahí si que hay coincidencia con la propuesta del Grup Promotor per a la Convenció Constitucional - sería deseable que la constitución fuera votada por bloques - todo ello en un plazo de aproximadamente dos años, durante los cuales se seguiría funcionando al amparo del marco normativo preexistente.

En suma, y a lo que se puede ver, todo un abanico de posturas, que irían desde las más conservadoras del Consell Assessor para la Transició Nacional, para el que la celebración de elecciones constituyentes es un requisito matizable, la mayoría exigible en sede parlamentaria no tendría porque ser la absoluta, la participación popular en el proceso es un simple aditamento al mismo, y el referéndum de ratificación sería válido con cualquier porcentaje de participación y cualquier tipo de mayoría, hasta las más radicales del Grup Promotor per a la Convenció Constitucional, o de Procés Constituent, para quienes el proceso constituyente en ciernes debería generar un cambio mucho más profundo que el derivado de sustituir una norma jurídica por otra.

42 Para una exposición más detallada de la idea, consúltese LópEZ, J.: «Una Constitució del segle XXI per a Catalunya», Ara.cat de 29.12.2014. En torno al desarrollo actual de la primera fase de ese proceso constituyente, véase López, J.: «Crònica de l'inici d'un (possible) procés constituent», en PACHECO, J. y López, J.: «L'elaboració democràtica de la Constitució», Àmbits de Política i Societat. Revista del Col.legi de Politòlegs $i$ Sociòlegs de Catalunya (2015) (en línea en http:/lambitscolpis.com/lelaboracio-democratica-de-la-constitucio/). Para una contextualización del mismo, y de los modelos tenidos en cuenta para su vertebración, véase LópEz, J. y Vilajosana, J. M.: «Democràcia en l'elaboració de la constitució: convencions constitucionals del segle XXI», en López, J. (dir.) y Vilajosana, J. M.: Qualitat democràtica per a un nou Estat, Fundació Josep Irla, Barcelona, 2014.

43 Vid. CARdús I CARdellach, P.: «Com serà el procés constituent del nou Estat català? [entrevista con Oriol Vidal-Aparicio]», en línea en www.procesconstituent-terrassa.cat/oriol-vidal-aparicio/. 


\section{CONCLUSIONES}

Sin ningún género de dudas, la más seria de las objeciones que cabe interponer respecto de los seis proyectos constitucionales que acabamos de desbrozar es la bien obvia de que siendo Cataluña parte integral de la nación española, encontrándose su derecho a la autonomía sustentado en —y articulado a partir de - lo dispuesto en la vigente Constitución, y hallándose ésta fundamentada «en la indisoluble unidad de la nación española», los ciudadanos de Cataluña carecen del derecho a segregarse unilateralmente de España y en consecuencia de darse una Constitución propia. Se trata de una objeción capital, de fondo - aunque también de forma-, y a día de hoy insalvable, que deslegitima ab initio la pretensión de todos y cada uno de los citados proyectos de llegar a convertirse en una Constitución para Cataluña.

Dicho esto, entrañaría un flaco favor a la Ciencia del Derecho, a la convivencia entre los españoles, y al legítimos derechos de los catalanes de profundizar en su autogobierno escudarse en esa objeción de principio para renunciar a todo intento de desentrañar el contenido de estos proyectos constitucionales por entender que su palmaria inconstitucionalidad hace ociosas cualesquiera otras consideraciones. Las instituciones autonómicas de Cataluña, y de manera palmaria su Parlament en la resolución de 9 de noviembre de 2015 ${ }^{44}$, han hecho patente su voluntad de avanzar en el proceso de segregación en curso al objeto de crear «un estado catalán independiente en forma de república», abriendo «un proceso constituyente ciudadano, participativo, abierto, integrador y activo para preparar las bases de la futura constitución catalana», y de hacerlo sin supeditarse «a las decisiones de las instituciones del Estado español, en particular del Tribunal Constitucional, que considera falto de legitimidad y de competencia», sino únicamente a las normas y mandatos emanados de la propia cámara, como por otra parte lo llevan planteando desde hace años varias de las fuerzas políticas más significativas del mapa político catalán. De modo que no resulta descabellado aventurar que en un momento dado cualquiera de estos proyectos pueda servir de base para el desarrollo de un texto constitucional con visos de aplicabilidad práctica, o incluso — una vez se rompe con los principios, nada impide hacerlo también con las formas- que alguno de ellos acabe convirtiéndose, mediante el simple fiat de alguna de las instituciones en liza, en la Constitución de facto de una Cataluña independiente.

Es este punto de vista el que justifica el análisis precedente, del que se derivan al menos dos conclusiones.

La primera de ellas obliga a apuntar a un dato quizás tan obvio - y también tan grave- como el anterior: que ninguno de los proyectos analizados cuenta a

44 «Resolució 1/XI del Parlament de Catalunya sobre l'inici del procés polític a Catalunya com a conseqüència dels resultats electorals del 27 de setembre de 2015», Butlletí Oficial del Parlament de Catalunya n. ${ }^{\circ} \mathrm{XI} / 7$, de 9 de noviembre de 2015, pp. 3 a 5 ()disponible en línea en www.parlament.cat). 
día de hoy con el más mínimo refrendo popular, o respaldo institucional. Todos sin excepción son ejercicios de voluntarismo llevados a cabo por invividuos o grupos, las más de las veces de representatividad dudosa, y en todo momento carentes del apoyo formal — cosa muy distinta es la simpatía, la sintonía política, o la coincidencia de fines - de ninguna de las instituciones catalanas de autogobierno estatutariamente reconocidas y actualmente operantes, y que además tampoco han dado el paso de contrastar a posteriori sus resultados con la opinión pública - y menos aun, el cuerpo electoral — de Cataluña. Si las constituciones son, además de normas jurídicas de obligado cumplimiento, documentos de clara significación política, cuya gestación no debería venir sino de la mano de un amplísimo consenso social, que idealmente debería rebasar con holgura las exigencias numéricas formalmente necesarias para la debida conformación de una mayoría entre el electorado o en el parlamento, es indiscutible que ninguno de los proyectos constitucionales analizados satisface esta legítima exigencia.

La segunda, obliga a volver sobre la cuestión a la que más atención hemos dedicado en las páginas precedentes: la de la baja calidad técnica que presentan, casi sin excepción, todos los proyectos constitucionales analizados. Si las constituciones son, además de documentos de clara significación política, normas jurídicas de obligado cumplimiento, resulta imprescindible que se hallen redactadas con una extrema minuciosidad, toda vez que cualquier disfunción, ambigüedad, laguna, o contradicción podría andando el tiempo desembocar en un conflicto entre las instituciones, o - peor incluso- en una merma de las garantías para los ciudadanos. Y ese es exactamente el caso con el que nos encontramos aquí: textos en los que se obvian derechos de la mayor relevancia, de los que los ciudadanos de Cataluña vienen ya disfrutando al amparo de la constitución vigente y que además forman ya parte del patrimonio común del constitucionalismo europeo; en los que se pasan por alto cuestiones clave de la organización territorial o institucional, o por el contrario se regulan éstos con un nivel de detalle propio de un reglamento administrativo; en los que se recogen sistemas electorales disparatados, o sencillamente inaplicables, o modelos de encaje interinstitucional proclives al autoritarismo; o sencillamente plagados de imprecisiones y puestos en circulación incluso sin haber sido depurados de sus erratas.

Es evidente que ambas carencias se hallan estrechamente interrelacionadas. El Derecho constitucional no lleva dos siglos debatiendo en torno a cómo articular de manera eficaz un proceso constituyente sin razón para hacerlo: redactar una constitución requiere forzosamente del intercambio de ideas, del encaje de intereses, del aprovechamiento de las experiencias, y — claro está- de cierta destreza en el manejo de las categorías jurídicas que solo está al alcance de parlamentarios o asambleístas democráticamente legitimados, técnicamente cualificados o al menos dotados de equipos de asesores de probada profesionalidad, y consagrados al debate en el marco de asambleas dotadas de reglas de procedimiento adecuadas, en contacto con la sociedad a la que van a servir, y dispuestas a nutrirse de sus experiencias y conocimientos previos. Y nada de eso ha suce- 
dido en el caso de los proyectos que acabamos de desgranar. A este respecto mueve al asombro que todos ellos hayan ignorado el hecho de que Cataluña - en tanto que sociedad económicamente desarrollada y democráticamente avanzada - cuente con una destacadísima nómina de constitucionalistas de primera fila, encuadrados en universidades e institutos, públicos y privados, solventes y prestigiosos, y en no pocos casos comprometidos con el llamado Procés, que podrían haber hecho aportaciones capitales a su redacción. Tanto, como que sus redactores hayan despreciado sin más las soluciones adoptadas por los Estatutos de Autonomía de 1979 y 2006 — que, pese a sus defectos, han sido refrendados por 1'8 millones de catalanes en el segundo caso, y 2'3 en el primero $^{45}$, y que han gobernado además las instituciones catalanas durante casi cuatro décadas ya - en beneficio de construcciones artificiosas y que a menudo ni siquiera cuentan con el aval del Derecho comparado.

Así las cosas, no cabe sino concluir poniendo muy seriamente en duda la capacidad de todos y cada uno de estos proyectos para, en su actual estado de elaboración, incrementar la eficiencia y la representatividad de las instituciones de autogobierno con las que Cataluña cuenta en la actualidad, ni mucho menos mejorar el sistema de derechos y libertades del que vienen disponiendo los ciudadanos de esta comunidad.

Title: What Constitution for Catalonia? A Critical Approach to the Constitutional Drafts of the Current Pro-independence Process

ABSTRACT: In a political situation characterized by the undeniable radicalization of the nationalist parties that have been governing Catalonia since 2010, as expressed by the repeated demonstration of their intention to secede from Spain - either through negotiation or by a unilateral declaration of independence-, and by the inescapable existence of a numerically important and socially influential public opinion in favor of the separation, the objective of this essay is, firstly, to record the successive draft constitutions for a future independent Catalonia that have been made public in recent months in the middle of this so-called "process"; then to clarify and sistematize their contents, noting its shortcomings, and highlighting the most relevant aspects —and also the more controversial ones - of their provisions; to assess their real chances of ever becoming standard legal norms; and —ultimately - to find some common features to all of them in order to better understand the ultimate objectives of Catalan separatism as regards the constitutional configuration of the State that it aspires to conform.

RESUMEN: En un momento político caracterizado por la innegable radicalización de los partidos nacionalistas que desde 2010 gobiernan Cataluña, concretada en la reiterada manifestación de su intención de separarse de España — bien de manera negociada, bien mediante una declaración unilateral de independencia-, y por la insoslayable existencia de una corriente de opinión numéricamente importante y socialmente muy influyente favorable a esa separación, el objetivo de este trabajo es el de levantar acta de los sucesivos proyectos o borradores de constitución para una futura Cataluña independiente surgidos en los últimos meses a la sombra de este asíllamado «proceso», para a continuación tratar de desbrozar su contenido, advertir de sus

45 Vid. «Constitución Española: Referendos» (en línea en www.congreso.es/consti/elecciones/referendos). 
carencias, poner de relieve los aspectos más relevantes — y también más controvertidos — de su articulado, y valorar sus posibilidades reales de llegar a convertirse alguna vez en norma jurídica, y —en última instancia - tratar de hallar algunos rasgos comunes a todos ellos que permitan entender mejor los objetivos últimos del secesionismo catalán en lo tocante a la configuración constitucional del Estado que aspira a conformar.

KEY WORDS: Catalonia, independence, nationalism, constitution-making, constitution.

Palabras Clave: Cataluña, independencia, nacionalismo, proceso constituyente, constitución.

FECHA DE RECEPCIÓN: 24.12.2015 FECHA DE ACEPTACIÓN: 15.01.2016 